\title{
Neuronal Cell Death in Alzheimer's Disease Correlates with apoE Uptake and Intracellular A $\beta$ Stabilization
}

\author{
Frank M. LaFerla, ${ }^{\star}$ Juan C. Troncoso, ${ }^{\sharp}$ Dudley K. Strickland, ${ }^{\ddagger}$ Claudia H. Kawas, and Gilbert Jay* \\ $*$ Department of Virology and ${ }^{\ddagger}$ Deparment of Biochemistry, Jerome H. Holland Laboratory, Rockville, Maryland 20855; and ${ }^{\S}$ Department \\ of Pathology and $\|^{\prime D e p a r t m e n t ~ o f ~ N e u r o l o g y, ~ J o h n s ~ H o p k i n s ~ U n i v e r s i t y ~ S c h o o l ~ o f ~ M e d i c i n e, ~ B a l t i m o r e, ~ M a r y l a n d ~} 21205$
}

\begin{abstract}
The brains of individuals with Alzheimer's disease (AD) are characterized by extracellular deposition of $\beta$-amyloid protein $(A \beta)$, intracellular neurofibrillary tangles, and loss of neurons. To study molecular markers associated with dying cells in the AD brain, in situ DNA labeling techniques were used to visualize cells with DNA fragmentation. We observed that intracellular accumulation of apolipoprotein $\mathrm{E}$ (apoE) is correlated with the detection of intracellular $A \beta-$ like immunoreactivity within the same cytoplasmic granules, suggesting that uptake of lipids may have stabilized the hydrophobic $A \beta$ protein within the cell. These apoEcontaining neurons also exhibit high expression of a cell surface receptor, gp330, which is known to bind apoE. Cells containing significant nuclear DNA fragmentation express the highest level of cell surface gp330. Extracellular deposition of $A \beta$ is detected only upon neuronal cell death, initially as halos of $A \beta$ immunoreactivity around individual dying neurons, and subsequently as $\mathrm{A} \beta$ plaques containing numerous neuronal cell ghosts. Based on our in situ analysis of nuclear DNA fragmentation, we conclude that neuronal cell death likely occurs before the extracellular deposition of $\mathrm{A} \beta$ in AD brains. (J. Clin. Invest. 1997. 100:310-320.) Key words: Alzheimer's disease $-\beta$-amyloid protein - apolipoprotein $\mathrm{E} \cdot$ glycoprotein 330 • apoptotic cell death
\end{abstract}

\section{Introduction}

A defining histopathological feature of Alzheimer's disease $(\mathrm{AD})^{1}$ is the presence of diffuse and neuritic plaques localized to specific brain regions, particularly the temporal lobe (1). The principal constituent of these extracellular deposits is the

Address correspondence to Dr. Gilbert Jay, Department of Virology, Jerome H. Holland Laboratory, 15601 Crabbs Branch Way, Rockville, MD 20855. Phone: 301-738-0801; FAX: 301-738-0410. The present address of Dr. Frank M. LaFerla is Department of Psychobiology, University of California, Irvine, CA 92697.

Received for publication 26 August 1996 and accepted in revised form 21 April 1997.

1. Abbreviations used in this paper: $\mathrm{A} \beta, \beta$-amyloid peptide; $\mathrm{AD}$, Alzheimer's disease; APP, $\beta$-amyloid precursor protein; H\&E, hematoxylin and eosin; LDLR, LDL receptor; LRP, LDL receptor-related protein; PAS, periodic acid Schiff; TUNEL, terminal deoxynucleotidyl transferase-biotin dUTP nick-end labeling; VLDLR, VLDL receptor.

J. Clin. Invest.

(C) The American Society for Clinical Investigation, Inc.

0021-9738/97/07/0310/11 \$2.00

Volume 100, Number 2, July 1997, 310-320
39-43 amino acid $\beta$-amyloid peptide $(A \beta)(2,3)$, which is derived by proteolytic processing from the $\beta$-amyloid precursor protein (APP). The shorter A $\beta$ fragments, particularly $A \beta 1-$ 40 , appear to be the predominant soluble species, while $A \beta 1-$ 42 is the form initially deposited in diffuse plaques (4). The generation of $A \beta$ from APP has been shown to be a normal processing event (5-7), and $A \beta$ can be detected in the cerebrospinal fluid and plasma of both normal and AD patients (6-8). The biochemical process leading to $A \beta$ accumulation in the diseased brain, however, is unknown.

The neurological deficits that occur in AD likely stem from neuronal cell dysfunction and death (9-11). The factors and circumstances that induce the dysfunction and death of neurons in the AD brain remain to be elucidated. Although there has been some controversy as to whether plaque accumulation correlates with dementia, recent evidence indicates that the $\mathrm{A} \beta$ load in $\mathrm{AD}$ brains can be correlated with the severity of dementia (12). In vitro and in vivo investigations using transgenic mice indicate that the $\mathrm{A} \beta$ peptide is toxic to neurons, and that cell death proceeds via an apoptotic pathway (13-16). Nevertheless, many questions regarding the pathobiological effects of $A \beta$ in the human brain remain unresolved (5-7). For instance, is $A \beta$ neurotoxic in its natural environment, and if so how? Where and how is $A \beta$ generated, and how does it assume an extracellular location? Does $A \beta$ exert its function after extracellular deposition?

We have used in situ DNA labeling techniques $(17,18)$ in an attempt to identify pathological markers that are associated with damaged cells in the AD brain. Our results indicate that there is substantial detection of damaged cells in the AD brain after terminal deoxynucleotidyl transferase-biotin dUTP nickend labeling (TUNEL) staining, a finding that correlates well with previous studies (19-21). Importantly, we find that many of these damaged neuronal cells contain $A \beta$-like immunoreactivity and apolipoprotein E (apoE) immunoreactivity. Although apoE immunoreactivity has been demonstrated previously in neurons $(22,23)$, we believe our results are the first to document it in damaged cells. In addition, a receptor (gp330) that is known to bind apoE is also found selectively elevated in these damaged cells. The sum of these findings suggests that gp330 receptor-mediated uptake of apoE may result in the intracellular stabilization of $\mathrm{A} \beta$, and may contribute to the demise of the cell.

\section{Methods}

Tissues and histology. Tissues from neuropathologically defined AD cases, which fulfilled the requirements of the Consortium to Establish a Registry for the Diagnosis of Alzheimer's Disease (24), were used. Comparable brain regions from $\mathrm{AD}$ and control cases were matched for age and postmortem delay as closely as possible, and were processed in parallel for all staining procedures. Sections of paraffinembedded tissues were cut at 5- $\mu \mathrm{m}$ thickness, and were stained with hematoxylin and eosin (H\&E), Bielschowsky's silver stain, thioflavin, 
periodic acid Schiff (PAS), or processed for TUNEL or immunohistochemistry $(15,16)$.

TUNEL. Several enzymatic methods have been used to detect apoptosis at the single-cell level by capitalizing on the fragmented nature of the DNA to add labeled or conjugated nucleotides to the termini. These techniques either involve tailing DNA by terminal deoxynucleotidyl transferase (TdT), referred to as the TUNEL method (17), or nick-translation with DNA polymerase I or the Klenow fragment, referred to as in situ nick-translation (25). The tailing method has been demonstrated to be superior to nick-translation for the detection of apoptotic cells; in contrast, necrotic cells in which the DNA is randomly fragmented were labeled preferentially by nick-translation (26). Although caution must be applied in interpreting the TUNEL assay (18), this assay in combination with other morphologic or biochemical criteria could allow for discrimination of apoptotic cells from necrotic cells.

Paraffin sections were dewaxed, rehydrated, and digested with proteinase $\mathrm{K}(20 \mu \mathrm{g} / \mathrm{ml})$. Endogenous peroxidase was quenched by treatment in $3 \%$ hydrogen peroxide. Sections were then rinsed in water and labeled at $37^{\circ} \mathrm{C}$ for $30 \mathrm{~min}$ with $\mathrm{TdT}(0.5 \mathrm{U} / \mu \mathrm{l})$ in a cocktail consisting of $25 \mathrm{mM}$ Tris, $\mathrm{pH}$ 6.6, $200 \mathrm{mM}$ potassium cacodylate, 1 $\mathrm{mM} \mathrm{CoCl}, 0.25 \mathrm{mg} / \mathrm{ml}$ bovine serum albumin, and $2 \mu \mathrm{M}$ biotindUTP. Sections were rinsed and incubated with avidin and biotinylated horseradish peroxidase (Vector Laboratories Inc., Burlingame, $\mathrm{CA}$ ), rinsed in water, and then stained with either diaminobenzidine or with True Blue (Kirkegaard and Perry Laboratories, Gaithersburg, MD).

Immunohistochemical staining. For immunohistochemical analysis of $A \beta$, the mouse monoclonal antibody $4 \mathrm{G} 8$, which is directed against an epitope consisting of amino acids 17-24 of $A \beta$ and recognizes diffuse and senile plaques in $\mathrm{AD}$ brains (27), or an antibody to amino acids 1-28 of $A \beta$ (15) was used. For apoE staining, the monoclonal antibody $3 \mathrm{H} 1$ and a rabbit polyclonal antibody (28) were used. Characterization of the rabbit polyclonal antibody R239 to gp330 (29), monoclonal antibody 8G1 (30), polyclonal antibody R777 to LDL receptor-related protein (LRP) (31), monoclonal antibody C7 to LDL receptor (LDLR) (32), and rabbit polyclonal antibody R2623 to VLDL receptor (VLDLR) (33) have been described previously. Paraffin sections were dewaxed and rehydrated. Sections were then rinsed in PBS, blocked for $1 \mathrm{~h}$ with $2 \%$ blocking serum, and incubated overnight with the appropriate antibody. This was followed by a brief rinse, incubation with a secondary antibody, PBS rinse, and incubation with avidin and biotinylated horseradish peroxidase (Vector Laboratories). All immunostained sections were developed with diaminobenzidine substrate.

\section{Results}

Analysis of cellular DNA fragmentation in AD brain. We have analyzed brain specimens from $\mathrm{AD}$ patients (who were at various stages in the progression of disease) based on clinical history, total brain weight at autopsy, and extracellular $\mathrm{A} \beta$ deposition on immunohistopathological analysis. Without exception, brain tissue sections from all seven AD patients showed extensive cellular DNA fragmentation as revealed by TUNEL. In contrast, sparse or no TUNEL-positive cells were detected in five of six brains from control individuals (Table I). The exceptional control sample in which TUNEL-positive cells were detected was from a 101-yr-old man who had a clinical history of depression. Since results obtained with the TUNEL assay are a reflection of the extent of cellular DNA damage, and by inference a measure of cell death, our results indicate that there are considerable numbers of damaged or dying cells in the AD brain tissue specimens compared to control samples. Since adjoining regions of the brain frequently have markedly different numbers of TUNEL-positive cells, at-
Table I. Clinical and Pathological Characteristics of Case Material

\begin{tabular}{lccccl}
\hline Case & Sex & Diagnosis & Brain weight & TUNEL & \multicolumn{1}{c}{ Brain regions } \\
\hline 1002 & F & AD & 1140 & + & HC, STG \\
1081 & M & AD & 1100 & + & HC, STG \\
1084 & F & AD & 1020 & + & HC, STG \\
1112 & F & AD & 1210 & + & HC, STG \\
1173 & F & AD & 830 & + & HC, STG \\
1240 & M & AD & 1235 & + & HC, MFG, STG \\
1250 & F & AD & 1050 & + & HC, MFG, S\&MTG \\
0532 & M & C & 1170 & - & TP \\
0780 & F & C & 1225 & - & HC, STG \\
0783 & M & C & 1410 & - & HC, STG \\
0868 & F & C & 1290 & - & IF, TP \\
0960 & M & C & 1200 & + & HC, SP \\
0989 & M & C & 1370 & - & MFG, STG \\
& & & & & \\
\hline
\end{tabular}

$I F$, inferior frontal gyrus; $H C$, hippocampus; $M F G$, middle frontal gyrus; $M T G$, middle temporal gyrus; $S P$, superior parietal; $S T G$, superior temporal gyrus; $T P$, temporal pole; $C$, control.

tempts to quantitate the overall extent of cell death in each of the patients have proven difficult, and may not be particularly informative. This finding correlates well with several prior studies (19-21).

Regardless of the individual, all regions of the brain with extensive TUNEL staining invariably showed surrounding extracellular $A \beta$ immunoreactivity. Characteristic differences, however, were observed for most individuals. A representative sample shown in Fig. $1 a$, shows the deep cortical layers of the superior temporal gyrus of AD patient 1250, in which TUNELpositive cells of varying intensities are interspersed among numerous TUNEL-negative cells. It is important to note the different intensities of TUNEL staining, which likely reflect various levels of cellular DNA fragmentation. Furthermore, in accord with only a minority of the cells containing detectable DNA damage, weak extracellular $A \beta$ immunoreactivity with the appearance of diffuse plaques was localized to this brain region (Fig. $1 \mathrm{~b}$ ). The lack of mature neuritic plaques in this area suggests that this brain region may have only recently been affected pathologically. In contrast, the superior temporal gyrus from AD patient 1173 showed subregional specificity, where an area with most cells being intensely TUNEL-positive was found abutting an area with much fewer and less intense TUNEL-positive nuclei (Fig. $1 c$ ). Analysis of a serial section with anti-A $\beta$ antibody indicated that the area with the large number of TUNEL-positive cells also contained numerous diffuse plaques, whereas the adjoining area with fewer TUNELpositive cells had barely any detectable extracellular $\mathrm{A} \beta$ immunoreactivity (Fig. $1 d$ ).

Not surprisingly, the region of the brain with the most extensive TUNEL-positive cells varied from individual to individual. For instance, the inferior temporal cortex of AD patient 1112 showed a uniformity of intense TUNEL-positive cells (Fig. $1 e$ ) and a corresponding increase in $\mathrm{A} \beta$ immunoreactivity (Fig. $1 f$ ). A serial section stained by H\&E was unremarkable except for a detectable change in the nuclear morphology of most cells (Fig. $1 \mathrm{~g}$ ). Bielschowsky silver stain revealed early indications of dystrophic neurites in association with the diffuse $\mathrm{A} \beta$ deposits (Fig. $1 \mathrm{~h}$ ). In addition, we also observed occa- 

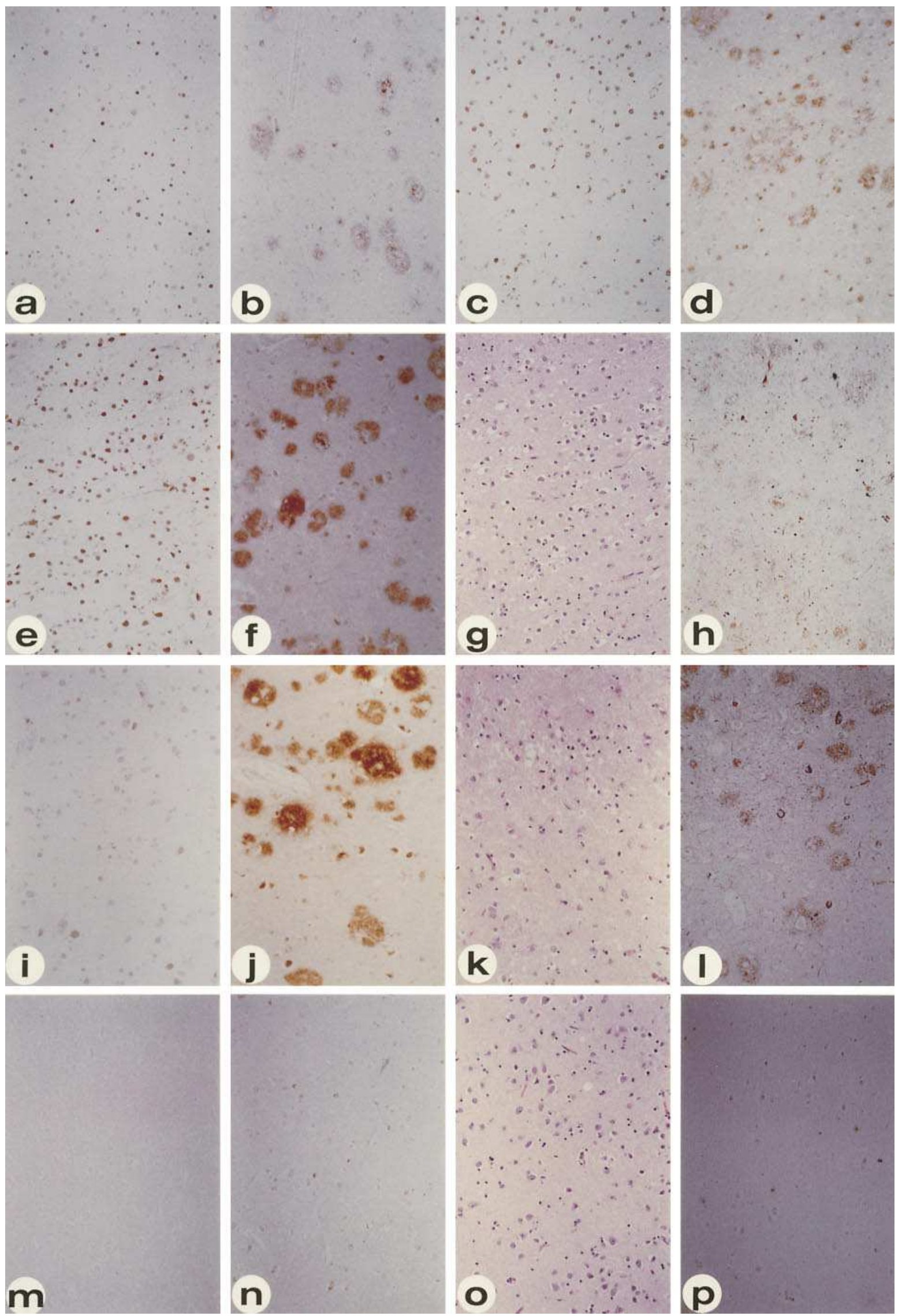
sional cells with intracellular neurofibrillary tangles that were also TUNEL-positive. Notably, since most of the AD patients exhibited regional cellular DNA damage, the lack of TUNELpositive cells in regions where $A \beta$ immunoreactivity was not detected provided an internal control for the absence of cell death resulting from postmortem changes.

AD patient 1002 was exceptional among the cases studied, in that intense $\mathrm{A} \beta$ immunoreactivity (Fig. $1 j$ ) in association with dystrophic neurites (Fig. $1 l$ ), was found throughout the gray matter, regardless of the brain region analyzed. A representative histological section from this patient is shown. Interestingly, although the majority of cells in the superficial layers of the superior temporal gyrus showed evidence of DNA fragmentation, they were weakly detectable by TUNEL. Since $H \& E$ staining revealed that the brain parenchyma was spongiotic, possibly reflecting the dropout of cells, and cell nuclei were all highly condensed and pyknotic (34), this suggests that these cells have progressed to a terminal stage of the cell death pathway (Fig. $1 k$ ). Furthermore, this finding indicates that the TUNEL method cannot be used to detect effectively dead cells in which the cellular DNA has been totally degraded.

Representing brain samples from five of the six controls, the temporal pole of sample 532 showed not even a single TUNEL-positive cell (Fig. $1 \mathrm{~m}$ ), had no extracellular A $\beta$ deposition (Fig. $1 n$ ), revealed no changes in cell morphology (Fig. $1 \mathrm{o}$ ), and had no detectable neuritic abnormalities (Fig. $1 p$ ). Significantly, postmortem changes that might have resulted from the delay in processing of the brain samples did not yield any background staining after the TUNEL method. Occasional TUNEL-positive cells were found scattered throughout sample 960 (from a 101-yr-old man suffering from clinical depression but with no known history of AD), but extracellular $\mathrm{A} \beta$ deposition was not detected anywhere (data not shown). This finding may be representative of normal aging rather than AD.

Intracellular $A \beta$ correlates with cell death. To investigate the relationship between extracellular $\mathrm{A} \beta$ deposition and cell death, tissue sections from the AD brains were analyzed for small foci of TUNEL-positive cells, which we posited represent the earliest evidence of cell death, to determine whether extracellular $\mathrm{A} \beta$ immunostaining invariably was associated with them. Since many of the AD patients had extensive plaques confined to focal subregions of the brain, it was relatively easy to locate small clusters of TUNEL-positive cells in areas that otherwise appeared histologically normal. In each of those areas containing small foci of cells with DNA damage, not only did we not detect any extracellular $A \beta$ deposition, but rather we observed intracellular $A \beta$-like immunoreactivity. A representative sample (Fig. $2 a$ ) shows the subiculum of AD patient 1,112 , where small focal areas of perhaps 50-100 cells are observed, some of which were intensely TUNEL-positive, and others that were only weakly labeled. $A \beta$ immunostaining revealed no evidence of extracellular $A \beta$ plaques in the immediate vicinity, but showed intracellular $A \beta$-like immunoreac- tivity of varying extent in most of the cells within the cluster (Fig. 2 b). The 4G8 monoclonal antibody used for this analysis is directed against an epitope consisting of amino acids 17-24 of $A \beta$, and recognizes diffuse and senile plaques in $\mathrm{AD}$ brains, although it cannot be ruled out that it may recognize APP as well (27). Detection of thioflavin S-reactive deposits (Fig. $2 h$ ) within cells with intracellular $\mathrm{A} \beta$ immunoreactivity (Fig. $2 f$ ), however, suggests accumulation of the $A \beta$ protein in these neurons. While we cannot exclude the possibility that the intracellular $A \beta$ reactivity might result from uptake from the extracellular compartment, our failure to detect $A \beta$ plaques in the vicinity may argue against this suggestion. It has to be pointed out that the various methods used, such as TUNEL, immunohistochemistry, and thioflavin staining, have different intrinsic sensitivities, and attempts to draw conclusions from such a study are dependent upon the assumption that changes detected by each method can be compared directly.

Although the TUNEL staining was predominantly intranuclear, the $\mathrm{A} \beta$ immunostaining was exclusively cytoplasmic. The gradation of TUNEL and $A \beta$ reactivities may suggest that cell death in these areas was restricted to cells with intracellular $A \beta$-like immunoreactivity, and that cells with a higher level of $A \beta$ accumulation were more prone to undergo cell death. Such findings were not restricted to a specific subtype of neurons, based on their morphological appearance and geographical location. In the CA3 region of the hippocampus of $\mathrm{AD}$ patient 1240, focal groups of neurons had acquired a spindleshaped morphology, showed intense TUNEL reactivity (Fig. $2 c$ ), and demonstrated cytoplasmic accumulation of $A \beta$ immunoreactivity (Fig. $2 d$ ). Again, no extracellular $\mathrm{A} \beta$ deposition could be detected in the vicinity, although we cannot exclude the possibility that the TUNEL staining observed in the cell body stems from long-distance neuritic damage incurred in an area enriched with extracellular $\mathrm{A} \beta$.

The presence of intracellular $A \beta$-like immunostaining appeared to occur without detectable extracellular $A \beta$ plaques, although the presence of extracellular $A \beta$ deposits predicted the coexistence of intracellular $A \beta$. Every brain region from every AD patient with either diffuse or neuritic plaques contained intermingling cells with intracellular $A \beta$-like immunoreactivity, albeit at different cellular densities and staining intensities (Fig. 1, $b, d, f$, and $j$ ). Intracellular $\mathrm{A} \beta$-like immunoreactivity was detected not just with the mouse monoclonal antibody (4G8), but also with a rabbit polyclonal antibody against $A \beta 1-28$ (15), and the immunostaining could be competed out using the immunizing $A \beta$ peptide (data not shown). Interestingly, somewhat similar but much less intense intracellular immunostaining was also observed in some of the control brains (Fig. $1 n$ ). Unlike that observed in AD patients, however, only few scattered cells that were not organized into defined foci were stained. More importantly, they were never correlated with TUNEL staining, possibly because the level of $\mathrm{A} \beta$ was below threshold for inducing cellular damage. Control brain sample 960 was exceptional in that an increase in the

Figure 1. Detection of cell death in the brain of AD patients. Analysis of paraffin-embedded brain sections $(6 \mu \mathrm{m})$ from different AD patients $(a-l)$ and from a representative control individual $(m-p)$ revealed a good correlation between the presence of TUNEL-positive cells and extracellular deposition of the A $\beta$ protein. Samples $a$ and $b$ are serial sections from the superior temporal gyrus (STG) of patient $1250 ; c$ and $d$, STG of patient 1173; $e-h$, the inferior temporal cortex of patient $1112 ; i-l$, STG of patient 1002; and $m-p$, the temporal pole of a non-AD control. Sections are stained by the TUNEL method $(a, c, e, i, m)$, for A $\beta$ with antibody $4 \mathrm{G} 8(b, d, f, j, n)$, by H\&E $(g, k, o)$, or by Bielschowsky's silver stain $(h, l, p) . \times 50$. 

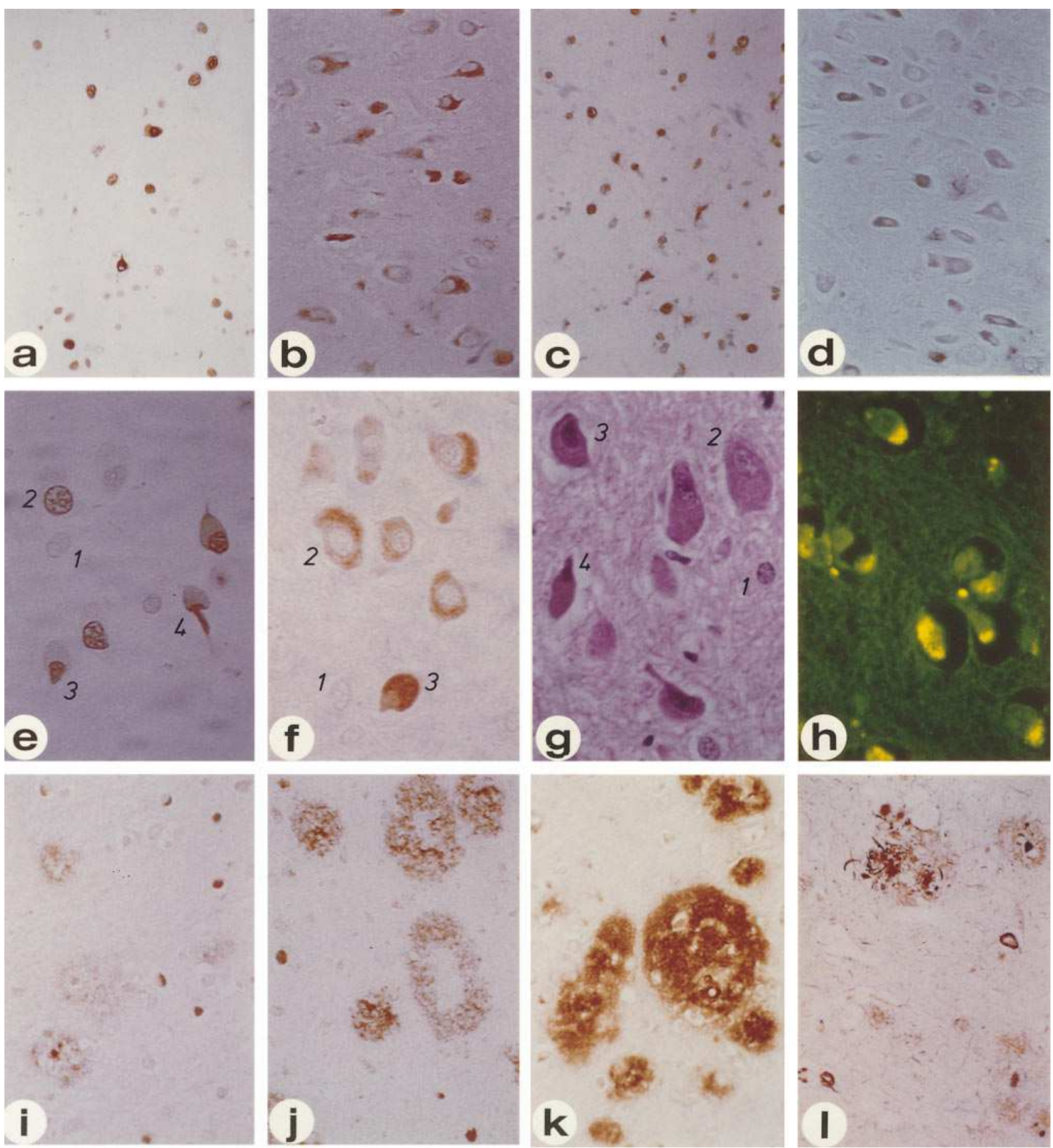

Figure 2. Evidence for extracellular deposition of $\mathrm{A} \beta$ upon cell death. Brain sections from AD patients were stained by the TUNEL method $(a, c, e)$, for A $\beta$ with antibody 4G8 $(b, d, f, i-k)$, by H\&E $(g)$, by thioflavin $\mathrm{S}(h)$, or by Bielschowsky's silver stain $(l)$. Samples $a$ and $b$ are serial sections from the subiculum of patient 1112; $c$ and $d$, the CA3 region of the hippocampus of patient $1240 ; e-h$, the lateral geniculate body of patient $1240 ; i-j$, the STG of patient $1173 ; k$ and $l$ the STG of patient $1002 . a-d, \times 100 ; e-h, \times 200 ; i-l, \times 100$.

Figure 3. Evidence for apoE uptake by dying neurons. Serial brain sections from an AD patient were stained by PAS (a), for apoE with antibody $3 \mathrm{H} 1(b)$, for $\mathrm{A} \beta$ with antibody $4 \mathrm{G} 8(c)$, for LRP with antibody $8 \mathrm{G} 1(d)$, for gp330 with antibody $1 \mathrm{H} 2(e$ and $g)$, by the TUNEL method using True Blue for visualization $(f)$, successively for gp330 with antibody $1 \mathrm{H} 2$ using $3,3^{\prime}$-diaminobenzidine, and by the TUNEL method using True Blue $(h)$, or by Bielschowsky's silver stain $(i) . \times 100$. 

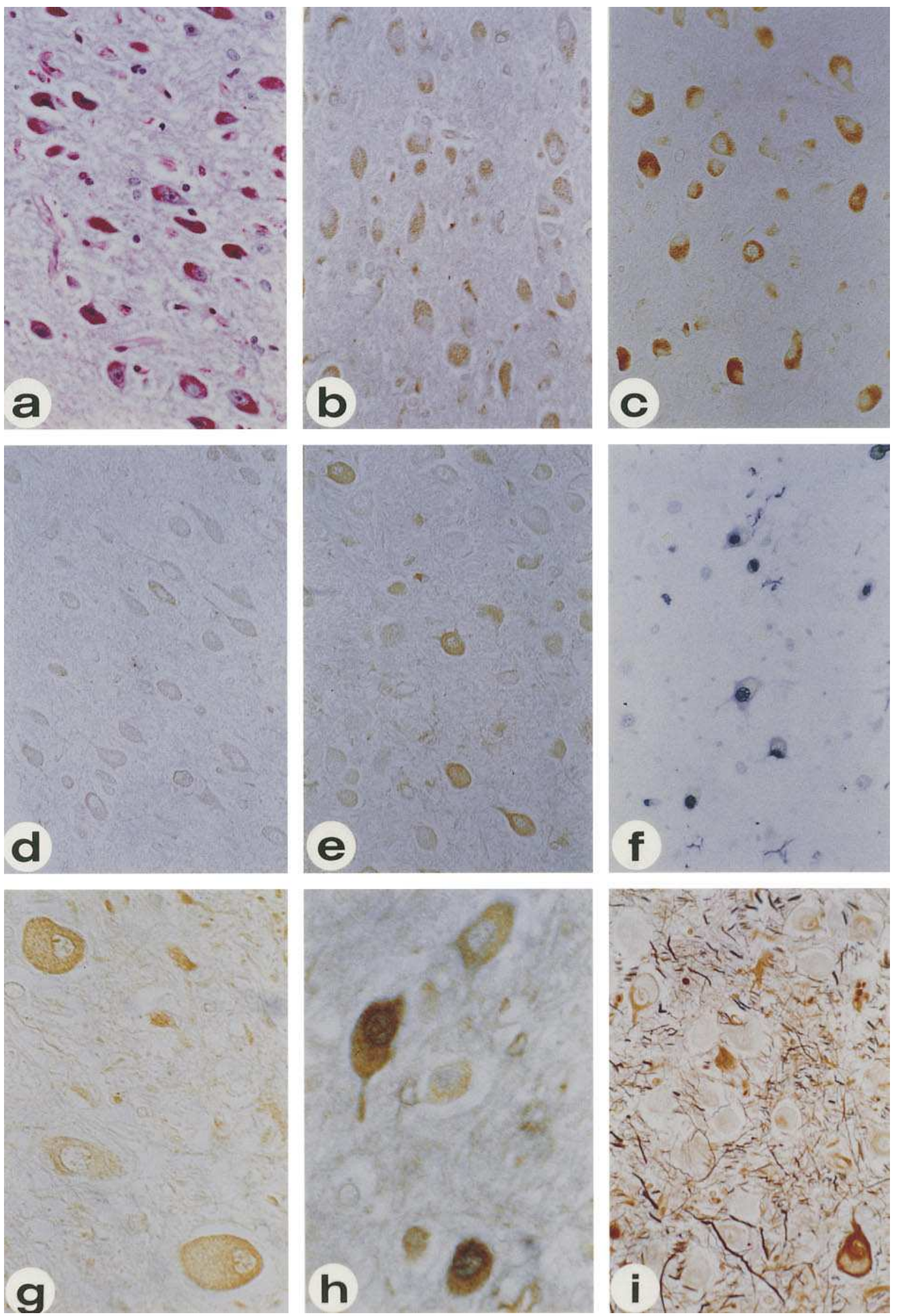
number of $A \beta$-reactive cells was correlated with TUNEL-positive cells.

Accumulating evidence indicates that apoptosis may play an important role in cell loss in AD $(14,15)$. Since the TUNEL assay can label cells that are dying by either apoptosis or necrosis (18), other criteria are required to define better the mechanism of cell death. Apart from TUNEL reactivity, we also observed a common series of morphological changes in many, but not all, of the TUNEL-positive cells in the AD brains that is more suggestive of cell death by apoptosis. Specifically, a high magnification view of the lateral geniculate body of patient 1240 showed cells at different stages of the apoptotic pathway (Fig. 2,e-h). Stage 1 cells were completely TUNELnegative with no detectable DNA fragmentation within their nuclei, and no detectable intracellular $A \beta$ reactivity. These cells were considered normal neurons. Stage 2 cells had somewhat enlarged nuclei with variable amounts of TUNEL staining due to the different extent of DNA fragmentation and marked expansion of the cytoplasmic compartment that had abundant $A \beta$-like immunoreactivity and thioflavin $S$-reactive deposits. We classified these as early-stage apoptotic cells that have not previously been identified morphologically. Stage 3 cells had TUNEL-positive nuclei that were somewhat condensed, and had lost their open chromatin morphology, as well as a cytoplasmic region that showed compact $A \beta$ immunostaining with increased basophilia and TUNEL-staining, suggesting nuclear leakage. These were intermediate-stage apoptotic cells. Stage 4 cells frequently had a crescent to panhandle shape where the collapsed TUNEL-positive nuclei appeared to be in the process of being extruded from one end of the cell. These were considered late-stage apoptotic cells.

apoE uptake correlates with intracellular $A \beta$ accumulation. In describing these stages, it appears that DNA fragmentation was preceded by a marked expansion of the cytoplasmic compartment of the cell that accommodated the accumulation of not just thioflavin S-reactive, A $\beta$-related material, but also coarse lipid granules, as defined by staining with either $H \& E$ or PAS (Fig. $3 a$ ). The PAS staining may be consistent with the accumulation of lipofuscin, a neuronal pigment for which biochemistry remains undefined (35). These granules were found invariably in the cytoplasm of neurons in each of the AD patients during every step of the apoptotic process (stages 2-4).

Since apoE isoforms are a major risk determinant for AD (18-21), and recognizing that apoE is the predominant lipid carrier in the central nervous system (36), we hypothesized that the PAS-positive, lipofuscin-like material in the neurons might contain apoE. To investigate this possibility, we performed immunohistochemical staining with both a monoclonal (3H1) and a polyclonal antibody (28). We found that the PASpositive cells contain varying levels of apoE-immunoreactivity, regardless of the antibody used (Fig. $3 \mathrm{~b}$ ). Interestingly, apoE has also been found to colocalize with $\mathrm{A} \beta$ within the same cytoplasmic granules (Fig. 3, $b$ and $c$ ). Since lipid-containing apoE has been shown to bind $A \beta(37-40)$, and the two have been detected as a complex in AD brains (41), it is possible that the intracellular accumulation of lipids serves to stabilize the hydrophobic $A \beta$ protein (or the proteolytic precursors from which it is derived).

As apoE is believed to be produced by glial cells in the CNS $(42,43)$, its accumulation in neurons is likely the result of receptor-mediated uptake $(22,23)$. Accordingly, we analyzed AD brains to determine if we could identify the receptor. Four members of the LDLR gene family have been shown to bind and internalize apoE in cultured cells; they are $\operatorname{LDLR}(44,45)$, VLDLR (46), LRP $(47,48)$, and gp330 $(49,50)$. We speculated that the receptor that is not normally activated but is inducible, is a likely candidate that is responsible for initiating a cascade of events leading to AD.

Using antibodies specific to each of the receptors, we investigated their expression profile in neurons from different brain regions. Both LDLR and VLDLR were detected indiscriminately at a very low level in both control and AD brains (data not shown). Similarly, LRP, while more easily detected, also did not discriminate between regions of the brain that did or did not contain AD lesions; in a serial section containing cells with varying levels of apoE and A $\beta$, LRP was found uniformly on the cell membrane and processes of every neuron (Fig. $3 d$ ), with either polyclonal antibody R777 (31) or monoclonal antibody $8 \mathrm{G} 1$ (30). On the other hand, gp330 was found in abundance almost exclusively on cells in the pathologically affected areas (Fig. $3 e$ ), with virtual sparing in normal regions except for an occasional cell with weak immunoreactivity. The immunostaining could be detected with either polyclonal antibody R239 (29) or monoclonal antibody 1 H2 (51). The immunostaining within the involved areas highlighted the cell membrane and its extensions, consistent with the location of a cell surface receptor (Fig. 3 g). Remarkably, the level of gp330 varied markedly between cells (Fig. $3 e$ ), reflecting perhaps both the differing levels of intracellular apoE (Fig. $3 b$ ) and the varying extent of DNA fragmentation (Fig. $3 f$ ). Indeed, in a double-labeling experiment, we have been able to demonstrate that cells with the highest gp330 expression have the highest intranuclear TUNEL reactivity (Fig. $3 h$ ). Of the four known receptors, only activation of gp330 correlated with DNA fragmentation and, possibly, the induction of apoptosis.

Interestingly, only an occasional cell with fragmented DNA was observed to show evidence of neurofibrillary tangles (Fig. $3 i$ ). Since the tangles were evaluated by Bielschowsky's silver stain, and not by immunohistochemical staining, it is possible that their numbers are slightly underrepresented. It did, however, appear that when present, these structures were found invariably around the periphery of the cell surrounding the collection of apoE- and $A \beta$-containing granules.

If the dying neurons contain $A \beta$-related material, it is possible that these molecules may be released to the surrounding parenchyma sometime during the apoptotic process, thereby giving rise to the extracellular $A \beta$ deposits. This is suggested by our findings with a transgenic mouse model, in which intracellular expression of $A \beta$ leads to neuronal cell death and formation of diffuse extracellular $A \beta$ deposits (16). To explore this possibility, we analyzed regions of the brain from AD patients with marginal extracellular $A \beta$ immunostaining. In the least involved regions, we observed diffuse plaques that were not much larger than the size of a neuron. For example, in the superior temporal gyrus of AD patient 1173 , anti-A $\beta$ immunostaining revealed numerous small halolike structures intermingled among neurons with intense intracellular $A \beta$ reactivity (Fig. $2 i$ ). Within the halos were frequently either an unstained cell ghost, or a darkly stained structure that resembled a collapsed cell. This finding suggested the diffusion of $A \beta$ away from dying neurons. In an adjoining region where extracellular $\mathrm{A} \beta$ immunostaining was more extensive, even larger but still well-defined halos were observed (Fig. $2 j$ ). This latter observation suggested that the $A \beta$ protein became insoluble in the 
extracellular environment shortly after its release from the dying cell. In fact, these early structures were observed in every AD patient analyzed, and were found interspersed among advanced plaques.

We observed that many of the larger anti-A $\beta$ immunostained structures from the superior temporal gyrus of AD patient 1002 had variable numbers of cell ghosts within them (Fig. $2 k$ ). Surrounding these large $A \beta$ deposits were invariably smaller $A \beta$ structures of different sizes. This observation is consistent with large neuritic plaques being derived from multiple neurons either dying simultaneously or in succession. The extent of coalescence of individual structures determines the ultimate size of the neuritic plaque. It is anticipated that such plaques will continue to enlarge with increased severity of cell death. Bielschowsky silver stain confirmed the frequent presence of multiple darkly stained cores within the same large neuritic plaque (Fig. $2 l$ ). The detection of dystrophic neurites within these plaques may suggest secondary involvement of neighboring neuritic and synaptic structures as well.

\section{Discussion}

Our findings indicate that neurons in the AD brain are particularly susceptible to accumulating DNA damage, and consequently to degenerate and die. Although TUNEL is not a definitive marker of apoptosis, it still allows identification of dying cells in situ. The number of damaged cells identified by TUNEL in the AD brain may appear unexpectedly high, but our results are comparable to those reported by others (19-21). It must be emphasized that the time scale for the demise of apoptotic cells has not been characterized in the adult brain, especially in response to chronic pathological stimuli. Potentially, these cells may acquire DNA damage, yet persist for some time before their eventual removal; this may, in fact, be reflected by the varying intensities of TUNEL staining that have been observed between individual cells within a region. Alternatively, it is possible that the extensive number of TUNEL-positive cells is part of a coordinated response that may have contributed to the death of the patient. In addition, since these damaged cells occur in focal areas of the AD brain and are not widely distributed, it indicates that cellular DNA fragmentation is a consequence of the disease process, and is not likely due to postmortem effects.

In this present study, morphological and biochemical endpoints were examined in defining some of the molecular events associated with cellular DNA fragmentation in the AD brain. Not only did we find that damaged cells detected by the TUNEL assay were generally localized in regions that contained extracellular $\mathrm{A} \beta$ deposition, but we also found that the extent of TUNEL staining could be correlated with the detection of intracellular $A \beta$-like immunoreactivity. Lassmann et al. (20) also reported that TUNEL-positive cells were positioned in brain regions containing extracellular $A \beta$ deposition. In this regard, although there has been some debate as to whether amyloid deposition correlates with the degree of dementia (10, 52), recent evidence indicates that the severity of dementia can be correlated with the $A \beta$ load (12). This does not, however, imply that other factors such as cytoskeletal abnormalities are not also involved in the disease process (53).

Although the site of $A \beta$ generation in vivo is unresolved, there is increasing evidence for its derivation or accumulation occurring intracellularly. The possibility that $A \beta$ accumulation occurs within cells, however, is controversial and difficult to verify in histological sections since $A \beta$ is derived from APP, and any $A \beta$-specific antibodies may concomitantly recognize various proteolytic fragments of APP as well. Nevertheless, analysis of various cell lines and animal models suggest that $\mathrm{A} \beta$ may occur within neurons: $(a)$ the Swedish mutation in the $A P P$ gene results in increased $A \beta$ accumulation in cultured cells (54); (b) $\mathrm{A} \beta$ can be directly immunoprecipitated from cell extracts of a neuronal-like cell line, NT2N (55); (c) the form of A $\beta$ deposited in plaques $(\mathrm{A} \beta 1-42)$ is resistant to intracellular degradation, but not to $\mathrm{A} \beta 1-40(56) ;(d)$ using transient transfection assays, intracellular expression of amyloidogenic fragments results in formation of amyloid-like fibrils that suffice to kill cells (57); (e) nonfibrillar A $\beta$ peptide exists intracellularly within neurons before the appearance of extracellular deposits of $A \beta$ in aged monkey brains (58); $(f)$ intracellular $A \beta$ immunoreactivity has been documented within dog brains (59); $(g)$ rabbits fed a high cholesterol diet accumulate $A \beta$ immunoreactivity within neurons (60); $(h)$ several reports indicate that $\mathrm{A} \beta$ is associated with intracellular neurofibrillary tangles $(43,61,62)$.

Based on our findings, the following sequence of events represents a plausible mechanism to account for extracellular $\mathrm{A} \beta$ deposition and cell death. The ability of neurons to synthesize $\mathrm{A} \beta$, which is a normal processing event, appears insufficient to assure intracellular $A \beta$ accumulation; other cofactors are required. The accumulation of $A \beta$ in neurons is facilitated by the presence of apoE, which may provide a suitable lipidic environment to stabilize the hydrophobic $A \beta$. The uptake of apoE from the surrounding environment appears to be dependent upon the neuronal expression of gp330, a member of the LDL receptor family, and on the apoE variant secreted by neighboring astrocytes as to whether it can efficiently bind gp330 (apoE3 and apoE4 can bind, but apoE2 cannot). Stabilization of $A \beta$ inside the neurons above a threshold level may trigger cell death. The death of neurons would result in the release of $A \beta$, possibly in a complex with apoE, which over time would evolve into neuritic plaques. While our findings suggest that intracellular accumulation of $A \beta$ may suffice to induce neuronal cell death which then leads to the extracellular deposition of $\mathrm{A} \beta$, it is also likely that the neuritic injury and glial activation resulting from the formation of senile plaques induce a second level of cell killing $(13,14,63)$; in that case, the extent of neuronal cell death can be amplified greatly.

The precise mechanism by which neurons die in the AD brain still remains to be determined. Defining the molecular mechanism may eventually contribute to the design of therapeutic interventions. It is likely, however, that both apoptotic and necrotic mechanisms will be involved in the neuronal cell death that occurs in AD brains. Accumulating evidence suggests that apoptosis is likely to be an important factor in AD pathology. In this regard, a role for $A \beta$ in inducing apoptosis in cell culture and in transgenic mice has been documented (14-16); however, whether the concentration of $\mathrm{A} \beta$ in the AD brain is adequate to induce directly apoptotic cell death is unclear. Furthermore, other gene products linked to familial early-onset AD, such as presenilin-2, have also been implicated as playing a role in apoptosis $(64,65)$.

The product of another AD-linked gene may also play a role in apoptosis through its interaction with $\mathrm{A} \beta$. The $A P O E$ genotype exerts a profound influence on the susceptibility of the individual to $\operatorname{AD}(37,66-68)$. Strittmatter et al. (37) have proposed that apoE functions as an isoform-specific stabilizer 
of $\mathrm{A} \beta$. The three major isoforms of the apoE protein, designated E2, E3, E4, are products of three alleles at a single gene locus (36). The predominant E3 molecule is considered the parental form, while E2 (Arg158 $\rightarrow$ Cys) and E4 (Cys112 $\rightarrow$ Arg) are considered variants. Specifically, the $\epsilon 4$ allele increases the risk and lowers the age of onset of $A D$, while the $\epsilon 2$ allele appears to decrease the risk and increase the age of onset. Indeed, Ohm et al. (69) have suggested that intraneuronal apoE appears a decade earlier as a function of the $\epsilon 4$ allele. Our suggestion that neuronal uptake of apoE is involved in $A \beta-$ induced cell death in the AD brain may explain why E4 exacerbates and E2 protects against the development of AD, since one known biochemical difference between the apoE variants is that $\mathrm{E} 4$ can efficiently bind the LDL receptor while E2 cannot (70). It is relevant to note that the ligand-binding domain of LDLR and gp330 are highly conserved (50). That activation of gp330 expression may be involved in the neurodegenerative process is intriguing. There have already been reports of apoE uptake into endosomes $(71,72)$ and studies on intracellular trafficking of apoE complexes (73). Additionally, there has been suggestion of $A \beta$ enhancing the uptake of apoE (74).

Pathological chaperones have been hypothesized to mediate amyloid formation $(75,76)$ and apoE has been shown to induce $A \beta$ aggregation and filament formation in cell-free systems $(39,40)$. Furthermore, $A \beta-$ apoE complexes have been isolated from $\mathrm{AD}$ brains (41). These observations are consistent with our findings that $A \beta$ and apoE colocalize in neurons, and our suggestion that association between the two within the cell may suffice to cause injury and trigger the apoptotic pathway. After cell death, $A \beta$ and apoE may be released as a complex $(37,41,77)$. We have observed that a key difference between a normal individual and an AD patient is the number of apoE-containing cells within a specific region of the brain. In control individuals, these cells are scattered, and the apparent level of apoE does not appear sufficient to cause cell death. In AD patients, these cells are found in clusters, and show both varying levels of intracellular apoE and different extent of nuclear DNA fragmentation. A highly related receptor, LRP, has been shown recently to be able to internalize APP, and to mediate its degradation (78). LRP and gp330 bind many ligands in common, and it is possible that gp330 may internalize APP as well. If so, the increased expression of gp330 would lead to not only increased apoE uptake, but also increased degradation of APP, thereby generating the pathological situation requisite for AD.

\section{Acknowledgments}

We thank Dr. H.M. Wisniewski and Dr. K.S. Kim for the 4G8 antibody, R. Milne for the $3 \mathrm{H} 1$ antibody, and Ms. Lisa Ruiz for assistance in the preparation of the manuscript.

We acknowledge the support of U.S. Public Health Service grant AG 05146, the Alzheimer's Association, and the Charles A. Dana Foundation.

\section{References}

1. Yankner, B.A. 1996. Mechanisms of neuronal degeneration in Alzheimer's disease. Neuron. 16:921-932.

2. Glenner, G.G., and C.W. Wong. 1984. Alzheimer's disease: initial report of the purification of a novel cerebrovascular amyloid protein. Biochem. Bio- phys. Res. Commun. 120:885-890.

3. Masters, C.L., G. Simms, N.A. Weinman, G. Multhaup, B.L. McDonald, and K. Beyreuther. 1985. Amyloid plaque core protein in Alzheimer disease and Down syndrome. Proc. Natl. Acad. Sci. USA. 82:4245-4249.

4. Iwatsubo, T., A. Odaka, N. Suzuki, M. Hidehiro, N. Nukina, and Y. Ihara. 1994. Visualization of $A \beta 42(43)$ and $A \beta 40$ in senile plaques with endspecific $A \beta$ monoclonals: evidence that an initially deposited species is A 342 (43). Neuron. 13:45-53.

5. Haass, C., M. Schlossmacher, A.Y. Hung, C. Vigo-Pelfrey, A. Mellon, B.L. Ostaszewski, I. Lieberberg, E.H. Koo, D. Schenk, D.B. Teplow, and D.J. Selkoe. 1992. Amyloid $\beta w$-peptide is produced by cultured cells during normal metabolism. Nature (Lond.). 359:322-325.

6. Shoji, M., T.E. Golde, J. Ghiso, T.T. Cheung, S. Estus, L.M. Shafer, X. Cai, D.M. McKay, R. Tintner, B. Frangione, and S.G. Younkin. 1992. Production of the Alzheimer amyloid $\beta$ protein by normal proteolytic processing. Science (Wash. DC). 258:126-129.

7. Busciglio, J., D.H. Gabuzda, P. Matsudaira, and B.A. Yankner. 1993. Generation of beta-amyloid in the secretory pathway in neuronal and nonneuronal cells. Proc. Natl. Acad. Sci. USA. 90:2092-2096.

8. Seubert, P., C. Vigo-Pelfrey, F. Esch, M. Lee, H. Dovey, D. Davis, S Sinha, M. Schlossmacher, J. Whaley, C. Swindlehurst, et al. 1992. Isolation and quantification of soluble Alzheimer's $\beta$-peptide from biological fluids. Nature (Lond.). 359:325-327.

9. DeKosky, S.T., and S.W. Scheff. 1990. Synapse loss in frontal lobe biopsies in Alzheimer's disease: correlation with cognitive severity. Ann. Neurol. 27: 457-464.

10. Terry, R.D., E. Maslieh, D.P. Salmon, N. Butters, R. DeTheresa, R. Hill, L.A. Hansen, and R. Katzman. 1991. Physical basis of cognitive alterations in Alzheimer's disease: synapse loss is the major correlate of cognitive impairment. Ann. Neurol. 4:572-580.

11. Scheff, S.W., and D.A. Price. 1993. Synapse loss in the temporal lobe in Alzheimer's disease. Ann. Neurol. 33:190-199.

12. Cummings, B.J., and C.W. Cotman. 1995. Image analysis of beta-amyloid load in Alzheimer's disease and relation to dementia severity. Lancet. 346: 1524-1528.

13. Yankner, B.A., L.R. Dawes, S. Fisher, K.L. Villa, G.M.L. Oster, and R.L. Neve. 1989. Neurotoxicity of a fragment of the amyloid precursor associated with Alzheimer's disease. Science (Wash. DC). 245:417-420.

14. Loo, D.T., A. Copani, C.J. Pike, E.R. Whittemore, A.J. Walencewicz, and C.W. Cotman. 1993. Apoptosis is induced by beta-amyloid in cultured central nervous system neurons. Proc. Natl. Acad. Sci. USA. 90:7951-7955.

15. LaFerla, F.M., B.T. Tinkle, C.J. Bieberich, C.C. Haudenschild, and G. Jay. 1995. The Alzheimer's A $\beta$ peptide induces neurodegeneration and apoptotic cell death in transgenic mice. Nat. Genet. 9:21-30.

16. LaFerla, F.M., C.A. Kappel-Hall, L. Ngo, and G. Jay. 1996. Extracellular deposition of $\beta$-amyloid upon p53-dependent neuronal cell death in transgenic mice. J. Clin. Invest. 98:1626-1632.

17. Gavrieli, Y., Y. Sherman, and S.S. Ben. 1992. Identification of programmed cell death in situ via specific labeling of nuclear DNA fragmentation. J. Cell Biol. 119:493-501.

18. Charriaut-Marlangue, C., and Y. Ben-Ari. 1995. A cautionary note on the use of the TUNEL stain to determine apoptosis. Neuroreport. 7:61-64.

19. Su, J.H., A.J. Anderson, B.J. Cummings, and C.W. Cotman. 1994. Immunohistochemical evidence for apoptosis in Alzheimer's disease. Neuroreport. 5:2529-2533.

20. Lassmann, H., C. Bancher, H. Breitschopf, J. Wegiel, M. Bobinski, K. Jellinger, and H.M. Wisniewski. 1995. Cell death in Alzheimer's disease evaluated by DNA fragmentation in situ. Acta Neuropathol. 89:35-41.

21. Smale, G., N.R. Nichols, D.R. Brady, C.E. Finch, and W.J. Horton. 1995. Evidence for apoptotic cell death in Alzheimer's disease. Exp. Neurol. 133:225-230.

22. Han, S.H., C. Hulette, A.M. Saunders, G. Einstein, M. Pericak-Vance, W.J. Strittmatter, A.D. Roses, and D.E. Schmechel. 1994. Apolipoprotein E is present in hippocampal neurons without neurofibrillary tangles in Alzheimer's disease and in age-matched controls. Exp. Neurol. 128:13-26.

23. Han, S.-H., G. Einstein, K.H. Weisgraber, W.J. Strittmatter, A.M. Saunders, M. Pericak-Vance, A.D. Roses, and D.E. Schmechel. 1994. Apolipoprotein $\mathrm{E}$ is localized to the cytoplasm of human cortical neurons: a light and electron microscopic study. J. Neuropathol. Exp. Neurol. 53:535-544.

24. Mirra, S.S., A. Heyman, and D. McKeel. 1991. The consortium to establish a registry for Alzheimer's disease (CERAD) part II. Standardization of the neuropathological assessment of Alzheimer's disease. Neurology. 41:479-486.

25. Wijsman, J.H., R.R. Jonker, R. Keijzer, C.J.H. van DeVelde, C.J. Cornelisse, and J.H. van Dierendock. 1993. A new method to detect apoptosis in paraffin sections: in situ end-labeling of fragmented DNA. J. Histochem. Cytochem. 41:7-21.

26. Gold, R., M. Schmied, G. Giegerich, H. Breitschopf, H.P. Hartung, K.V. Toyka, and H. Lassmann. 1994. Differentiation between cellular apoptosis and necrosis by the combined use of in situ tailing and nick translation techniques. Lab. Invest. 71:219-225.

27. Kim, K.S., D.L. Miller, V.J. Sapienza, C.J. Chen, C. Bai, I. GrundkeIqbal, J.R. Currie, and H.M. Wisniewski. 1988. Production and characterization 
of monoclonal antibodies reactive to synthetic cerebrovascular amyloid peptide. Neurosci. Res. Commun. 2:121-130.

28. Milne, R.W., P.H. Douste-Blazy, Y.L. Marcel, and L. Retegul. 1981. Characterization of monoclonal antibodies against human apolipoprotein E. $J$. Clin. Invest. 68:111-117.

29. Kounnas, M.Z., C.C. Haudenschild, D.K. Strickland, and W.S. Argraves. 1994. Immunological localization of glycoprotein 330, low density lipoprotein receptor related protein and $39 \mathrm{kDa}$ receptor associated protein in embryonic mouse tissue. In Vivo. 8:343-352.

30. Strickland, D.K., J.D. Ashcom, S. Williams, W.H. Burgess, M. Migliorini, and W.S. Argraves. 1990. Sequence identity between the $\alpha 2$-macroglobulin receptor and low density lipoprotein receptor-related protein suggests that this molecule is a multifunctional receptor. J. Biol. Chem. 265:17401-17404.

31. Kounnas, M.Z., R.E. Morris, M.R. Thompson, D.J. Fitzgerald, D.K. Strickland, and C.B. Saelinger. 1992. The $\alpha 2$-macroglobulin receptor/low density lipoprotein receptor-related protein binds and internalizes Pseudomonas exotoxin A. J. Biol. Chem. 267:12420-12423.

32. van Driel, J.R., J.L. Goldstein, T.C. Sudhof, and M.S. Brown. 1987. First cysteine-rich repeat in ligand-binding domain of low density lipoprotein receptor binds $\mathrm{Ca}^{2+}$ and monoclonal antibodies but not lipoproteins. J. Biol. Chem. 262:17443-17449.

33. Battey, F.D., M.E. Gafuels, D.J. Fitzgerald, W.S. Argraves, D.A. Chappell, J.F. Strauss, and D.K. Strickland. 1994. The 39-kDa receptor-associated protein regulates ligand binding by the very low density lipoprotein receptor. $J$. Biol. Chem. 269:23268-23273.

34. Majno, G., and I. Joris. 1995. Apoptosis, oncosis, and necrosis. Am. J. Pathol. 146:3-15.

35. Dowson, J.H. 1982. Neuronal lipofuscin accumulation in aging and Alzheimer dementia: a pathogenic mechanism. Br. J. Psychiatry. 140:142-148.

36. Mahley, R.W. 1988. Apolipoprotein E: cholesterol transport with expanded role in cell biology. Science (Wash. DC). 240:622-630.

37. Strittmatter, W.J., A.M. Saunders, D. Schmechel, V.M. Pericak, J. Enghild, G.S. Salvesen, and A.D. Roses. 1993. Apolipoprotein E: high-avidity binding to beta-amyloid and increased frequency of type 4 allele in late-onset familial Alzheimer disease. Proc. Natl. Acad. Sci. USA. 90:1977-1981.

38. LaDu, M.J., M.T. Falduto, A.M. Manelli, C.A. Reardon, G.S. Getz, and D.E. Frail. 1994. Isoform-specific binding of apolipoprotein $\mathrm{E}$ to $\beta$-amyloid. $J$. Biol. Chem. 269:23403-23406.

39. Ma, J., A. Yee, J. Brewer, S. Das, and H. Potter. 1994. The amyloidassociated proteins $\alpha$-antichymotrypsin and apolipoprotein $\mathrm{E}$ promote the assembly of the Alzheimer $\beta$-protein into filaments. Nature (Lond.). 373:92-94.

40. Sanan, D.A., K.H. Weisgraber, S.J. Russell, R.W. Mahley, D. Huang, A. Saunders, D. Schmechel, T. Wisniewski, B. Frangione, A.D. Roses, and W.J. Strittmatter. 1994. Apolipoprotein E associates with $\beta$-amyloid peptide of Alzheimer's disease to form novel monofibrils. J. Clin. Invest. 94:860-869.

41. Naslund, J., J. Thyberg, L.O. Tjernberg, C. Wernstedt, A.R. Karlstrom, N. Bogdanovic, S.E. Gandy, L. Lannfelt, L. Terenius, and C. Nordstedt. 1995. Characterization of stable complexes involving apolipoprotein $\mathrm{E}$ and the amyloid $\beta$ peptide in Alzheimer's disease brain. Neuron. 15:219-228.

42. Boyles, J.K. 1985. Apolipoprotein E associated with astrocytic glia of the central nervous system and with nonmyelinating glia of the peripheral nervous system. J. Clin. Invest. 76:1501-1513.

43. Pitas, R.E. 1987. Astrocytes synthesize apolipoprotein E and metabolize apolipoprotein E-containing lipoproteins. Biochem. Biophys. Acta. 917:148-161.

44. Brown, M.S., and J.L. Goldstein. 1986. A receptor-mediated pathway for cholesterol homeostasis. Science (Wash. DC). 232:34-47.

45. Kreiger, M., and J. Herz. 1994. Structures and functions of multiligand lipoprotein receptors: macrophages, scavenger receptors, and LDL receptorrelated protein (LRP). Annu. Rev. Biochem. 63:601-637.

46. Takahashi, S., Y. Kawarabayasi, T. Nakai, J. Sakai, and T. Yamamoto. 1993. Rabbit very low density lipoprotein receptor: a low density lipoprotein receptor-like protein with distinct ligand specificity. Proc. Natl. Acad. Sci. USA. 89:9252-9256.

47. Kowal, R.C., J. Herz, J.L. Goldstein, V. Esser, and M.S. Brown. 1989. Low density lipoprotein receptor-related protein mediates uptake of cholesteryl esters derived from apoprotein E-enriched lipoproteins. Proc. Natl. Acad. Sci. USA. 86:5810-5814.

48. Beisiegel, U., W. Weber, G. Ihrke, J. Herz, and K.K. Stanley. 1989. The LDL receptor-related protein, LRP, is an apolipoprotein E-binding protein. Nature (Lond.). 341:152-164

49. Willnow, T.E., J.L. Goldstein, K. Orth, M.S. Brown, and J. Herz. 1992. Low density lipoprotein receptor-related protein and gp330 bind similar ligands, including plasminogen activator-inhibitor complexes and lactoferrin, an inhibitor of chylomicron remnant clearance. J. Biol. Chem. 267:26172-26180.

50. Saito, A., S. Pierromonoco, A.K.C. Loo, and M.G. Farquhar. 1994. Complete cloning and sequencing of rat gp330/megalin, a distinctive member of the low density lipoprotein receptor gene family. Proc. Natl. Acad. Sci. USA. 91:9725-9729.

51. Zheng, G., D.R. Bachinsky, and I. Stamenkovic. 1994. Organ distribution in rats of two members of the low-density lipoprotein receptor gene family, gp330 and LRP/ $22 \mathrm{MR}$, and the receptor-associated protein (RAP). J. Histochem. Cytochem. 42:531-542.
52. Hyman, B.T., K. Marzloff, and P.V. Arriagada. 1993. The lack of accumulation of senile plaques or amyloid burden in Alzheimer's disease suggests a dynamic balance between amyloid deposition and resolution. J. Neuropathol. Exp. Neurol. 52:594-600.

53. Terry, R.D. 1996. The pathogenesis of Alzheimer disease: an alternative to the amyloid hypothesis. J. Neuropathol. Exp. Neurol. 55:1023-1025.

54. Martin, B.L., G. Schrader-Fischer, J. Busciglio, M. Duke, P. Paganetti, and B.A. Yankner. 1995. Intracellular accumulation of $\beta$-amyloid in cells expressing the Swedish mutant amyloid precursor protein. J. Biol. Chem. 270: 26727-26730.

55. Wertkin, A.M., R.S. Turner, S.J. Pleasure, T.E. Golde, S.G. Younkin, J.Q. Trojanowski, and V.M.-Y. Lee. 1993. Human neurons derived from a teratocarcinoma cell line express solely the 695 -amino acid amyloid precursor protein and produce intracellular $\beta$-amyloid or A4 peptides. Proc. Natl. Acad. Sci. USA. 90:9513-9517.

56. Knauer, M.F., B. Soreghan, D. Burdick, J. Kosmoski, and C.G. Glabe. 1992. Intracellular accumulation and resistance to degradation of the Alzheimer amyloid A4/B protein. Proc. Natl. Acad. Sci. USA. 89:7437-7441.

57. Maruyama, K., K. Terakado, M. Usami, and K. Yoshikawa. 1990. Formation of amyloid-like fibrils in COS cells overexpressing part of the Alzheimer amyloid protein precursor. Nature (Lond.). 347:566-569.

58. Martin, L.J., C.A. Pardo, L.C. Cork, and D.L. Price. 1994. Synaptic pathology and glial responses to neuronal injury precede the formation of senile plaques and amyloid deposits in the aging cerebral cortex. Am. J. Pathol. 145: $1358-1381$.

59. Cummings, B.J., J.H. Su, C.W. Cotman, R. White, and M.J. Russell. 1993. $\beta$-amyloid accumulation in aged canine brain: a model of early plaque formation in Alzheimer's disease. Neurobiol. Aging. 14:547-560.

60. Sparks, D.L., S.W. Scheff, J.C. Hunsaker, H. Liu, T. Landers, and D.R. Gross. 1994. Induction of Alzheimer-like $\beta$-amyloid immunoreactivity in the brains of rabbits with dietary cholesterol. Exp. Neurol. 126:88-94.

61. Grundke-Iqbal, I., K. Iqbal, L. George, Y.C. Tung, K.S. Kim, and H.M. Wisniewski. 1989. Amyloid protein and neurofibrillary tangles coexist in the same neuron in Alzheimer disease. Proc. Natl. Acad. Sci. USA. 86:2853-2857.

62. Perry, G., P. Cras, S.L. Siedlak, M. Tabaton, and M. Kawai. 1992. $\beta$ protein immunoreactivity is found in the majority of neurofibrillary tangles of Alzheimer's disease. Am. J. Pathol. 140:283-289.

63. Burdick, D., B. Soreghan, M. Kwon, J. Kosmoski, M. Knauer, A. Henschen, J. Yates, C. Cotman, and C. Glabe. 1992. Assembly and aggregation properties of synthetic Alzheimer's A4/beta amyloid peptide analogs. J. Biol. Chem. 267:546-554.

64. Vito, P., E. Lacana, and L. D'Adamio. 1996. Interfering with apoptosis: $\mathrm{Ca}^{2+}$-binding protein ALG-2 and Alzheimer's disease gene ALG-3. Science (Wash. DC). 271:521-525.

65. Deng, G., C.J. Pike, and C.W. Cotman. 1996. Alzheimer-associated presenilin-2 confers increased sensitivity to apoptosis in PC12 cells. FEBS (Fed. Eur. Biochem. Soc.) Lett. 397:50-54.

66. Corder, E.H., A.M. Saunders, W.J. Strittmatter, D.E. Schmechel, P.C Gaskell, G.W. Small, A.D. Roses, J.L. Haines, and V.M. Pericak. 1993. Gene dose of apolipoprotein E type 4 allele and the risk of Alzheimer's disease in late onset families. Science (Wash. DC). 261:921-923.

67. Rebeck, G.W., J.S. Reiter, D.K. Strickland, and B.T. Hyman. 1993. Apolipoprotein E in sporadic Alzheimer's disease: allelic variation and receptor interactions. Neuron. 11:575-580.

68. Payami, H., J. Kaye, L.L. Heston, T.D. Bird, and G.D. Schellenberg. 1993. Apolipoprotein E genotype and Alzheimer's disease. Lancet. $342: 738$

69. Ohm, T.G., M. Kirca, J. Bohl, H. Scharnagl, W. Grob, and W. Marz. 1995. Apolipoprotein E polymorphism influences not only cerebral senile plaque load but also Alzheimer-type neurofibrillary tangle formation. Neuroscience. 66:583-587.

70. Weisgraber, K.H., T.L. Innerarity, and R.W. Mahley. 1982. Abnormal lipoprotein receptor-binding activity of the human $\mathrm{E}$ apoprotein due to cysteine-arginine interchange at a single site. J. Biol. Chem. 257:2518-2521.

71. Jensen, T.G., A.D. Roses, and A.L. Jorgensen. 1994. Apolipoprotein E uptake and degradation via chloroquine-sensitive pathway in cultivated monkey cells overexpressing low density lipoprotein receptor. Neurosci. Lett. 180: 193-196.

72. Cataldo, A.M., D.J. Hamilton, J.L. Barnett, P.A. Paskevich, and R.A. Nixon. 1996. Properties of the endosomal-lysosomal system in the human central nervous system: disturbances mark most neurons in populations at risk to degenerate in Alzheimer's disease. J. Neurosci. 16:186-199.

73. Roses, A.D. 1995. Perspective: on the metabolism of apolipoprotein E and the Alzheimer diseases. Exp. Neurol. 132:149-156.

74. Scharnagl, H., K. Winkler, M. Huttinger, et al. 1996. The BA4 amyloid peptide enhances cellular uptake of apolipoprotein E-containing lipoproteins by the low-density lipoprotein receptor-related protein/alpha-2-macroglobulin receptor. In Apolipoprotein E and Alzheimer's Disease. A. Roses, K. Weisgraber, and Y. Christen, editors. Springer-Verlag, Berlin, Germany. 136-144.

75. Wisniewski, T., A. Golabek, E. Matsubara, J. Ghiso, and B. Frangione. 1993. Apolipoprotein E: binding to soluble Alzheimer's beta-amyloid. Biochem. Biophys. Res. Commun. 192:359-365.

76. Strittmatter, W.J., K.H. Weisgraber, D.Y. Huang, L.M. Dong, G.S. 
Salvesen, V.M. Pericak, D. Schmechel, A.M. Saunders, D. Goldgaber, and A.D. Roses. 1993. Binding of human apolipoprotein E to synthetic amyloid beta peptide: isoform-specific effects and implications for late-onset Alzheimer disease. Proc. Natl. Acad. Sci. USA. 90:8098-8102.

77. Namba, Y., M. Tomonaga, H. Kawasaki, E. Otomo, and K. Ikeda. 1991.

Apolipoprotein E immunoreactivity in cerebral amyloid deposits and neu- rofibrillary tangles in Alzheimer's disease and kuru plaque amyloid in Creutzfeldt-Jakob disease. Brain Res. 541:163-166.

78. Kounnas, M.Z., R.D. Moir, G.W. Rebeck, A.I. Bush, W.S. Argraves, R.E. Tanzi, B.T. Hyman, and D.K. Strickland. 1995. LDL receptor-related protein, a multifunctional ApoE receptor, binds secreted $\beta$-amyloid precursor protein and mediates its degradation. Cell. 82:331-340. 